Research Article, Issue 4
Analytical Methods in Environmental Chemistry Journal
JMECJ

\title{
Mercury determination in work place air and human biological samples based on dispersive liquid-liquid micro-extraction coupled with cold vapor atomic absorption spectrometry
}

\author{
Seyed Mojtaba Mostafavi a and Ali Ebrahimi ${ }^{\text {b,* }}$
}

${ }^{a}$ Department of Chemistry, Iranian-Australian Community of Science, Hobart, Tasmania, Australia

${ }^{b}$ Occupational Health Engineering Department, School of Public Health, Qom University of Medical Sciences, Qom, Iran

A R T I C L E I N F O:

Received 13 Sep 2019

Revised from 18 Nov 2019

Accepted 11 Dec 2019

Available online 28 Dec 2019

Keywords:

Mercury,

Analysis,

Dispersive liquid-liquid micro-

extraction,

Human blood,

Work place air

\begin{abstract}
A B S T RA C T
Mercury as a toxic heavy metal is important factor must be determined and controlled in work place air and human biological samples. It should be mentioned that, mercury $(\mathrm{Hg})$ get distinguished from other toxic environment pollutants, due to their non-biodegradability which accumulate in living tissues of human body. By NIOSH method, the briefing work place air of worker was measured by flow injection cold vapor atomic absorption spectrometry (FI-CV-AAS). For separation and preconcentration mercury from blood/urine samples, a new procedure based on benzyl 1H-pyrrole1-carbodithioate (BPDC; $\mathrm{C}_{12} \mathrm{H}_{11} \mathrm{NS}_{2}$ ) was used by ultrasonic liquid-liquid micro-extraction (ULLME) coupled with cold vapor atomic absorption spectroscopy (CV-AAS). The influences of various analytical parameters including $\mathrm{pH}$, BPDC concentration, sample volume and ionic liquid volume were investigated. The quantitative recoveries and enrichment factor were obtained more than $95 \%$ and 9.8 , respectively at $\mathrm{pH}=7$. The detection of limit (LOD) and detection of quantification (LOQ) of mercury were $30 \mathrm{ng} \mathrm{L}^{-1}$ and $0.1 \mu \mathrm{g} \mathrm{L}^{-1}$ respectively. In order to calculate the validation and accuracy of proposed method, the certified reference materials (NIST, CRM 3133 Lot 061204) was used and analyzed by ULLME-CVAAS. So, proposed method had good potential for preparation and preconcentration mercury in human blood / urine samples of worker and workplace air before analysis.
\end{abstract}

\section{Introduction}

Heavy metal is important factor must be controlled in environmental air and patients. There are some heavy metals with toxic effects such as mercury, cadmium, nickel, vanadium, arsenic, lead and aluminum which have no known beneficial effect on organisms. Mercury has been documented to cause autoimmune and neurological diseases. Mercury simply vaporizes at room temperature and easily enters to the environment and human

\footnotetext{
Corresponding Author: Ali Ebrahimi *

E-mail: Ali.Ebrahimi.ohe@gmail.com
}

https://doi.org/10.24200/th amecj.v2.i04.81 lungs. High concentration of mercury vapors in work place air can accumulate in human tissues as compared to non- occupationally exposed individuals. Adverse health effects of this exposure including subtle neurological side-effects have also been well documented in most Petrochemical workers even at the lowest levels of exposure; consequently, measurement of mercury and methyl mercury in blood, urine, hair and air briefing seems to be important [1-7]. Chlor-alkali workers are mostly exposed through breathing air of mercury vapors which was released from electrochemical system to human body such as lungs and skin. 
Family members of these workers may also become exposed to mercury through personnel's clothes contaminated with mercury particles. Ingested metallic mercury enters the body through the stomach or intestines but even in large amounts very little enters the body. On the other hand, breathing mercury vapors results in direct absorption of most it (about $80 \%$ ) from the lungs which rapidly moved to other organs, including the brain and kidneys. Mercury get distinguished from other toxic pollutants due to their non-biodegradability can accumulate in living tissues of human body. Even a very small amount of them can cause severe physiological or neurological damage to the human body [8-14]. The concentration of mercury vapor in air reported by occupational safety and health administration guidelines (OSHA, $0.1 \mathrm{mg} \mathrm{m}^{-3}$ ). In addition, national institute for occupational safety and health (NIOSH) has established a recommended exposure limit for mercury vapor of $0.05 \mathrm{mg} \mathrm{m}^{-3}$ for up to an 8-hour workday and a 40-hour workweek. American conference of governmental industrial hygienists (ACGIH) has assigned mercury vapor a threshold limit value of $0.025 \mathrm{mg} \mathrm{m}^{-3}$ for a normal eight-hour workday and a 40-hour work week .Mercury levels in blood can be used to help diagnose recent mercury exposure and to evaluate patient response to chelation therapy. Normal mercury concentration in human blood/urine is less than 10-20 $\mu \mathrm{g} \mathrm{L}^{-1}$ [15-19]. Many analytical methods such as atomic fluorescence spectrometry [20-24] high-performance liquid chromatography [25] Gas-chromatographic [26] plasma mass spectrometry [27] high-performance liquid chromatography on-line coupled with cold-vapor atomic fluorescence spectrometry $[28,29]$ gas chromatography-mass spectrometry [30] ion chromatography using photo-induced chemical vapor generation atomic fluorescence spectrometric detection [31] ion chromatography coupled with ICP-MS [32] liquid chromatography hyphenated to cold vapor atomic fluorescence spectrometry [33] UV-Vis spectrophotometric [34] were used for mercury spices determination. Samples preparation and preconcentration before analysis is an important factor for determination of pollutants in different matrixes. Recently, the various methods for the preparation and preconcentration of mercury compounds, including solid phase extraction (SPE) [35-43], gold trap [44], ionic liquid-based dispersive liquid-liquid microextraction (IL-DLLME) [45, 46], cloud point extraction (CPE) [47,48], electromembrane extraction [34], dispersive solid phase microextraction [49], single-drop microextraction [50], and Liquid-liquid extraction (LLE) [51], were reported. Since 2010, the DLLME method has been used for extraction and/or preconcentration of different analytes from aqueous samples [52, 53]. By DLLME method, extraction solvent such as ionic liquids, liquid phase (sample) and disperser solvent (acetone) was used [54]. The DLLME procedure has many advantages including simple, rapid, low time and cost, and efficient extraction. The green analysis such as, decrease solvent volume and less waste generation due to preparation and analysis samples was achieved [53-54]. In this study, the mercury concentration in human blood and urine samples based on BPDC -IL was determined by FI-CVAAS after ULLME procedure in 50 samples. In addition, 50 briefing air based on Hopcalite was analyzed by NIOSH method (6009).

\section{Experimental}

\subsection{Apparatus}

The experiments were performed using the flow injection cold vapor atomic absorption spectrometer (FI-CVAAS, GBC - 932, 3000, Australia). All containers (quartz crucibles, plastic tubes) were cleaned with detergent and treated successively by the hydrochloric acid and rinsed with de-ionized water. Microwave digestions were carried out with a multi-wave 3000 (Anton Paar, 100 mL, 20 bars; Austria). The pure argon gas (99.99\%) was used as a carrier gas for CV-AAS analysis and the $\mathrm{pH}$ values of the solutions were measured by a digital $\mathrm{pH}$ meter (Metrohm 744). Personal sampling pump, Sampler (glass tube, $7 \mathrm{~cm}$ long, 6-mm OD, $4 \mathrm{~mm}$ ID, flame sealed ends with plastic caps containing one section of $200 \mathrm{mg}$ Hopcalite held in place by 
glass wool plugs (SKC, Inc., Cat. Num. 226-17$1 \mathrm{~A}$, or equivalent) and BOD bottle were used for collection of air and blood/urine in the industrial factory respectively.

\subsection{Reagents and Materials}

All chemicals of analytical reagent grade such as nitric acid, hydrochloric acid, benzyl 1H-pyrrole-1carbodithioate (BPDC; $\mathrm{C}_{12} \mathrm{H}_{11} \mathrm{NS}_{2}$ ) (CAS no 6079538-2), Polyoxyethylene octyl phenyl ether (TX$100)$, and sodium borohydride (NaBH4) were from Merck Germany. Mercury standard solutions were prepared from a stock solution of $1000 \mathrm{mg} \mathrm{L}^{-1}$ in $1 \%$ nitric acid from Fluka Switzerland. Reducing agents (aqueous solution of $0.6 \%$ sodium borohydride in $0.5 \%$ sodium hydroxide) were prepared freshly and filtered before use. Ionic liquid (1-butyl-3methylimidazolium hexafluorophosphate; [BMIM] [PF6]; $\mathrm{C}_{8} \mathrm{H}_{15} \mathrm{~F}_{6} \mathrm{~N}_{2} \mathrm{P}$ ) (1-Ethyl-3-methylimidazolium hexafluorophosphate; [EMIM][PF6]; $\mathrm{C}_{6} \mathrm{H}_{11} \mathrm{~F}_{6} \mathrm{~N}_{2} \mathrm{P}$ ) (Trimethyl imidazolium hexafluorophosphate; [DMMIm][PF6]) was purchased from Sigma Aldrich. Buffer solutions were prepared from 2-1 mol L ${ }^{-1}$ sodium acetate and acetic acid for $\mathrm{pH}=$ 3-7. Ultrapure water was prepared from Millipore (Germany).

\subsection{Sampling}

For sampling, all glass tubes (sampling vessel) were washed with a $1 \mathrm{moL} \mathrm{L}^{-1} \mathrm{HNO}_{3} / \mathrm{HCl}$ solution for at least $24 \mathrm{~h}$ and rinsed 10 times with DW before using. Due to low mercury concentrations in whole blood/urine, even minor contamination at any stage of sampling, sample storage and handling, or analysis has the potential to effect on the accuracy of the results. $10 \mathrm{~mL}$ blood and $100 \mathrm{~mL}$ urine samples were collected from factory workers and healthy matched controls (20-55 years), living in Abadan (IRAN). For analysis of 45 blood samples, 5 microliter of heparin (free metals) was added. The human blood and urine sample was maintained at $-20{ }^{\circ} \mathrm{C}$ in a cleaned glass tube.

45 air samples were collected in an employee's breathing zone according to 6009 NIOSH analytical method. Each personal sampling pump was calibrated with a representative sampler and the end of sampler was broken immediately prior to sampling. Samplers were attached to the pumps with flexible tubing and air was collected at a rate of 200 to $300 \mathrm{~mL} \mathrm{~min}^{-1}$.

\subsection{General procedure}

In this research, human blood and urine and briefing air samples of factory workers were studied. The determination of mercury in blood/ urine and air was carried out using a flow injection cold vapor atomic absorption spectrometry system after sample treatment according to the ULLME procedure. Based on procedure, the BPDC as complexing agent was added to human samples and mercury extracted by ULLME as a new mode of liquid phase extraction with high recovery and extraction efficiency. In this work, $0.5 \mathrm{~mL}$ of $2 \%(\mathrm{w} / \mathrm{v})$ BPDC solution was prepared and added to $10 \mathrm{~mL}$ of blood and urine samples and $\mathrm{pH}$ was adjusted to 7 with buffer solution in a centrifuge tube. Then, $0.2 \mathrm{~g}$ of different IL was added to the mixtures and they were shaken with a vortex apparatus for $5 \mathrm{~min}$. Mercury $\left(\mathrm{Hg}^{\mathrm{II}}\right)$ was complexed and pre-concentrated as Hg-BPDC-IL ([BMIM][PF6]). The phases were separated by centrifuging of turbid solution at 4 min with 3500 $\mathrm{rpm}$. After separation of ionic liquid from liquid phase, the remained solution (Hg-BPDC-IL) was back extracted with nitric acid $(0.5 \mathrm{M}, 0.5 \mathrm{~mL})$ and the mercury concentration in blood/urine samples was determined by FI-CV-AAS (Fig 1).

Air samplers were capped and pack securely for shipment. Based on NIOSH procedure, the Hopcalite sorbent and the front glass wool plug from each sampler were placed in separate $50-\mathrm{ml}$ volumetric flasks and mixture of $2.5 \mathrm{~mL}$ of $\mathrm{HNO}_{3} /$ $\mathrm{HCl}$ concentration added to volumetric flasks. Hopcalite sorbent was dissolved in acids and diluted to $50 \mathrm{~mL}$ of deionized water (blue color), then the mercury concentration was determined with FI-CV-AAS.

\section{Results and Discussion}

Analytical conditions for mercury determination 


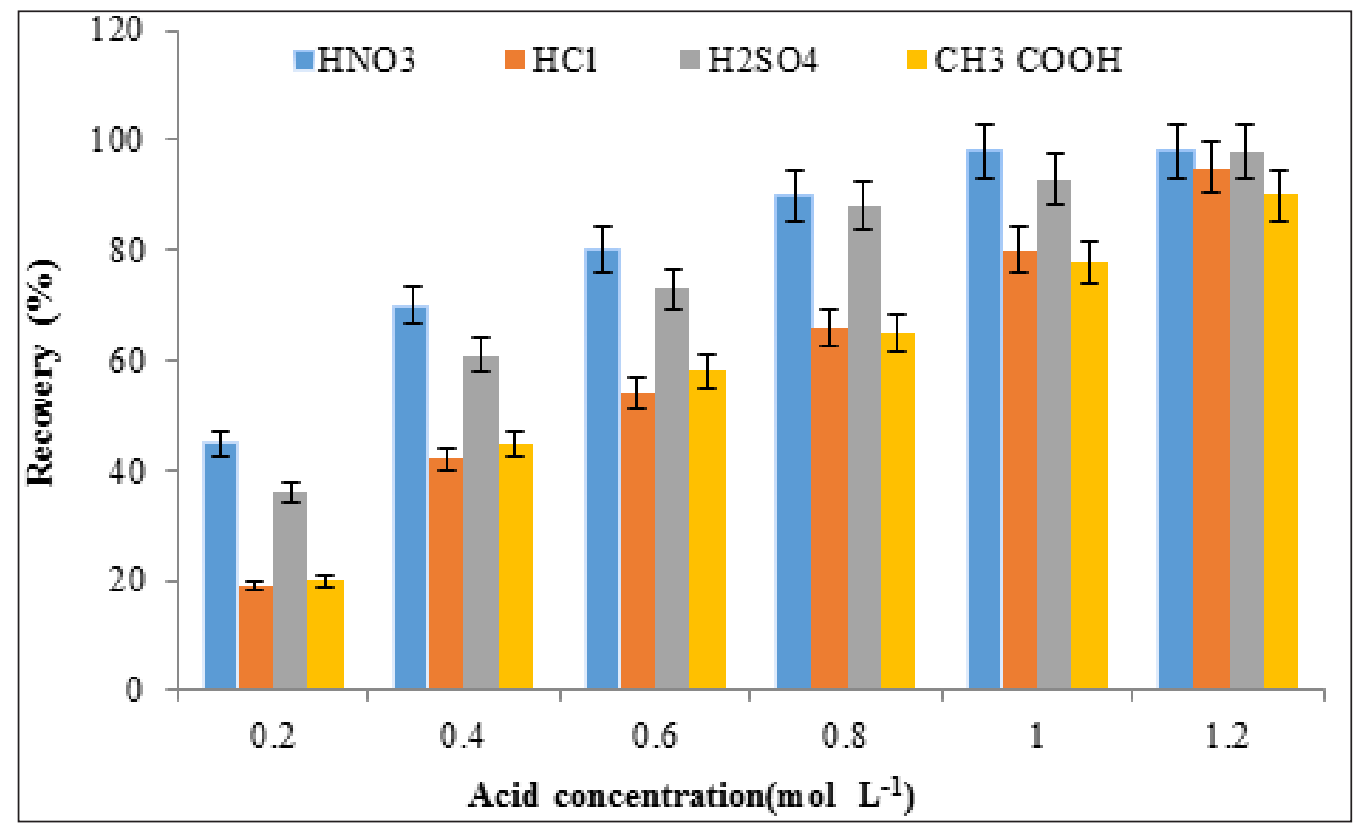

Fig. 1. Back extraction of Ionic liquid with different acids

were performed in briefing air and human blood and urine samples of chemical factory workers at this work. Absorption $(\mathrm{S} / \mathrm{N})$ and repeatability of the results were investigated for the determination mercury by FI-CVAAS. The instrumental and extraction conditions are listed in Table 1. Working range was between $0.05-7.1 \mu \mathrm{g} \mathrm{L} \mathrm{L}^{-1}$ for samples at peak area.

The complexation phenomenon is strongly conditioned by the $\mathrm{pH}$. The results showed us the

Table 1. Instrumental and extraction conditions for mercury determination by FI- CVAAS

\begin{tabular}{lc}
\hline Instrumental Parameters & Mercury \\
\hline Wavelength $(\mathrm{nm})$ & 253.7 \\
Lamp current $(\mathrm{mA})$ & $3-4$ \\
Spectral bandwidth $(\mathrm{nm})$ & 0.5 \\
LOD $\left(\mu \mathrm{g} \mathrm{L}^{-1}\right)$ & 0.2 \\
LOQ $\left(\mu \mathrm{g} \mathrm{L}^{-1}\right)$ & 0.6 \\
Working range $\left(\mu \mathrm{g} \mathrm{L}^{-1}\right)$ & $0.5-70$ \\
\hline ULLME method by BPDC & Mercury \\
\hline LOD $\left(\mu \mathrm{g} \mathrm{L}^{-1}\right)$ & 0.015 \\
LOQ $\left(\mu \mathrm{g} \mathrm{L}^{-1}\right)$ & 0.05 \\
Working range $(\mu \mathrm{g} \mathrm{L}-1)$ & $0.05-7.1$ \\
Enrichment Factor & 9.8 \\
Volume sample $(\mathrm{mL})$ & 10 \\
Amount of IL $(\mathrm{g})$ & 0.2 \\
pH & 7 \\
\hline
\end{tabular}

$\mathrm{pH}$ from 5.5 to 7.5 was good recovery for mercury extraction by BPDC. So $\mathrm{pH}=7$ selected as favorite $\mathrm{pH}$ for further analysis in blood samples (Fig 2). The minimum BPDC concentration necessary to achieve maximum extraction efficiency is $1.4 \times 10^{-6}$ moL L ${ }^{-1}$. So the $15 \times 10^{-6} \mathrm{moL} \mathrm{L}^{-1}$ was used by ULLME procedure (Fig 3).

Different ionic liquids were used by ULLME method. Based on Figure 4, maximum extraction was occurred by [BMIM][PF6]. The high extraction was observed by volume higher than $0.2 \mathrm{~mL}$ for [BMIM][PF6] (Fig. 4). The effect of sample volume was evaluated with different volume of blood and urine samples from 1-25 mL and quantitative extraction was observed in $10 \mathrm{~mL}$ of blood/urine sample (Fig. 5).

The concentration of $\mathrm{Hg}(\mathrm{II})$ based on BPDC as ligand was determined by ULLME procedure in blood and human samples which was coupled to spectrometerofFI-CVAAS. Inoptimized conditions, the means of five times determinations, for $\mathrm{Hg}$ (II) were obtained by proposed method. The real samples were spiked with standard concentration of $\mathrm{Hg}(\mathrm{II})$ in LLOQ and ULOQ of linear range at $\mathrm{pH}=7$ (Table 1). As validation methodology, the good accuracy results was achieved by spiking standard mercury species $\left(0.1-7.0 \mu \mathrm{g} \mathrm{L}^{-1}\right)$ to human 


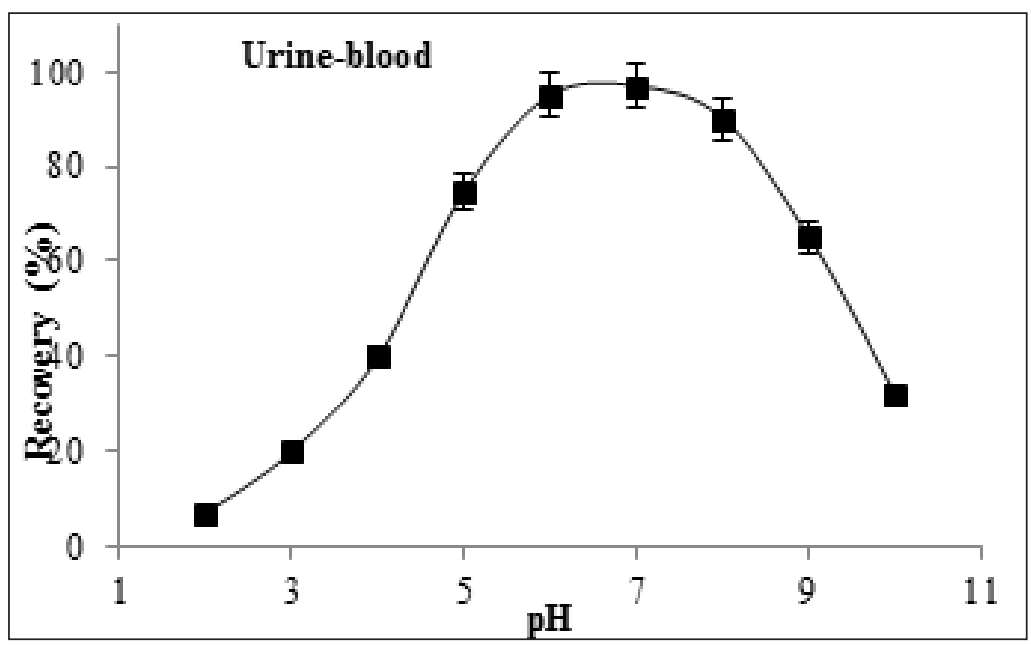

Fig. 2. Effect of $\mathrm{pH}$ on mercury extraction in human blood /urine samples

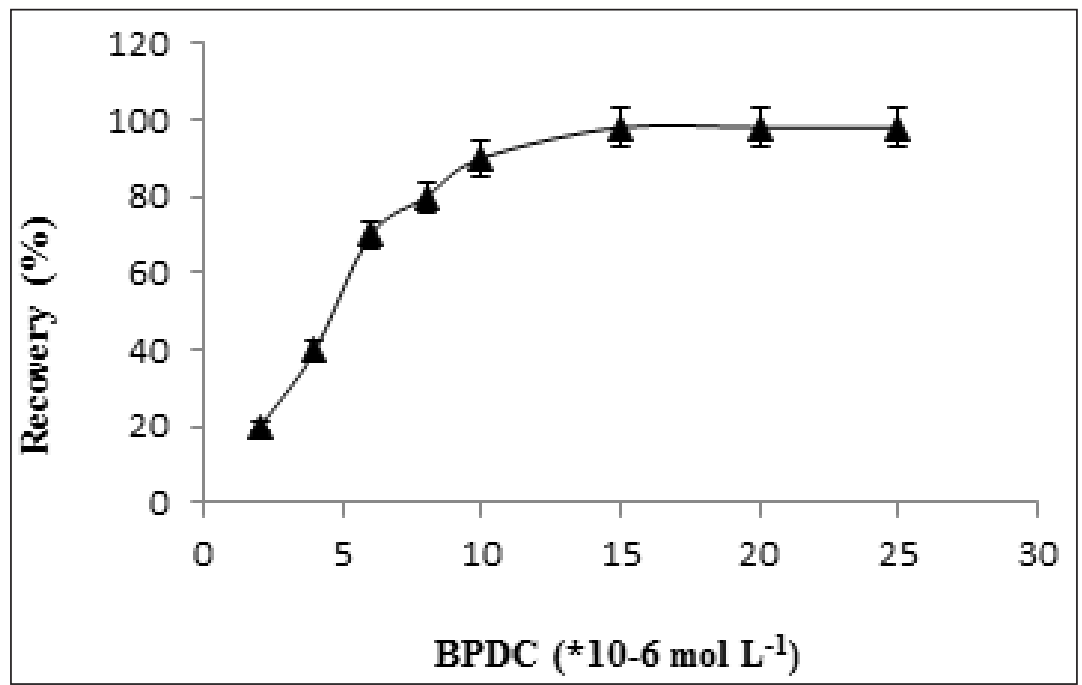

Fig. 3. Effect of BPDC on mercury extraction in human blood/urine samples

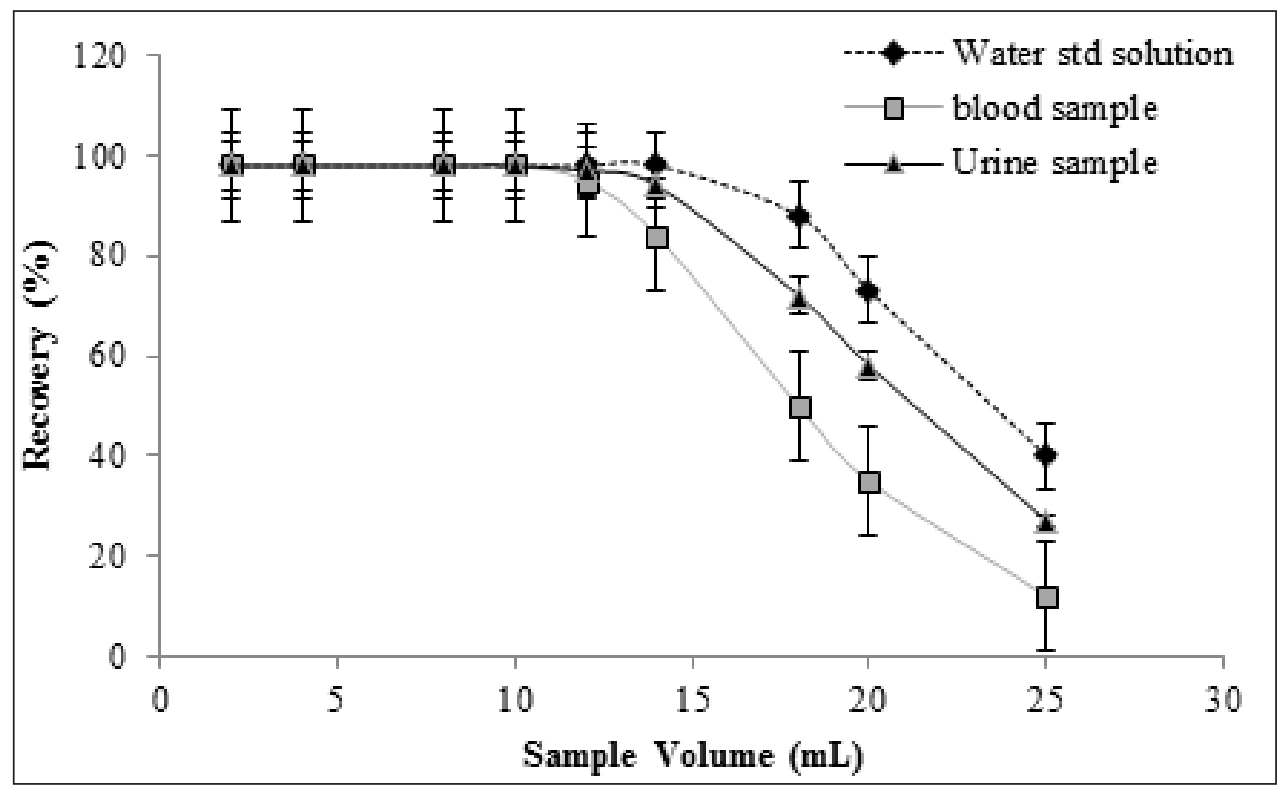

Fig. 4. Effect of sample volume on mercury extraction in human blood /urine samples 


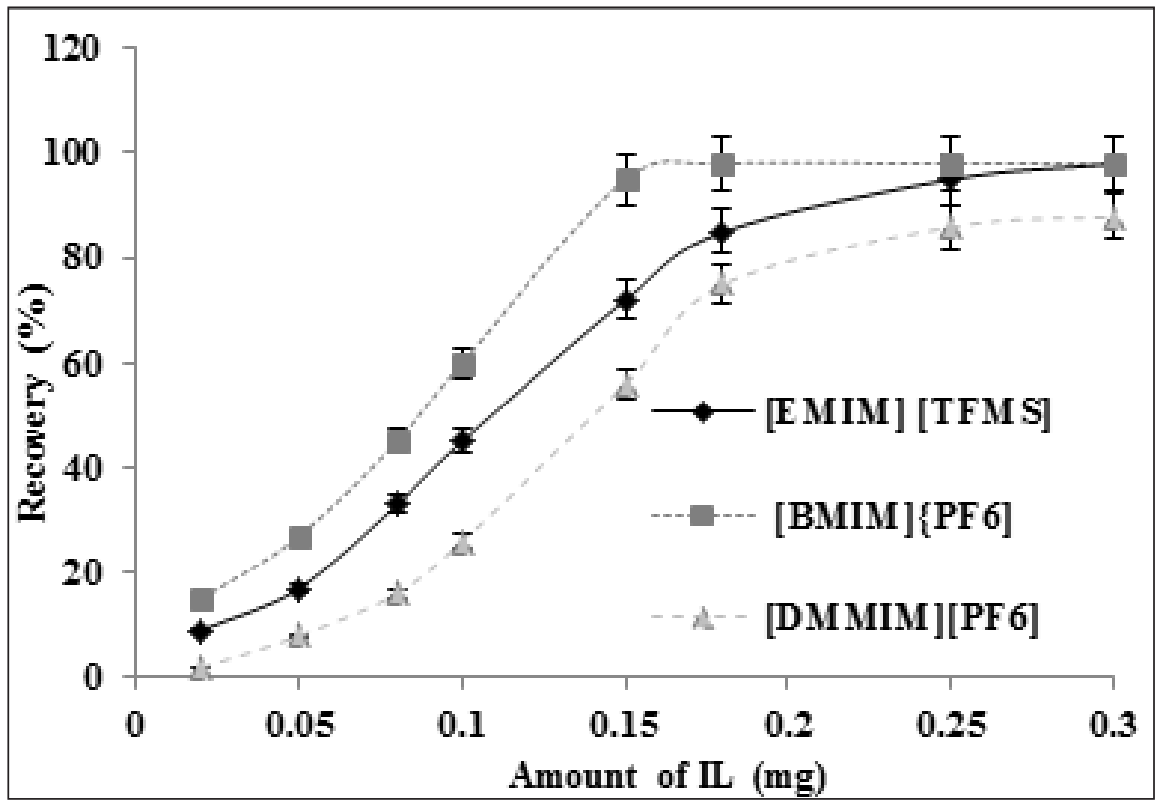

Fig. 5. Effect of ionic liquid on mercury extraction in human blood/urine samples

samples. Mercury concentrations in workers have higher than threshold limit value (TLV) and all of them have almost clinical problem. Validation of

Table 1. Validation of proposed method for determining blood mercury by BPDC $\left(\mu \mathrm{g} \mathrm{L}^{-1}\right)$

\begin{tabular}{lccc}
\hline Sample & $\begin{array}{c}\text { Added } \\
\text { mercury }\end{array}$ & $\begin{array}{c}\text { Found } \\
\text { mercury }\end{array}$ & $\begin{array}{c}\text { Recovery } \\
\text { (\%) }\end{array}$ \\
\hline Blood A & ----- & $2.33 \pm 0.09$ & ----- \\
& 2 & $4.26 \pm 023$ & 96.5 \\
& 4 & $6.28 \pm 035$ & 98.7 \\
\hline Blood B & ----- & $1.78 \pm 0.07$ & ----- \\
& 1 & $2 . .80 \pm 0.14$ & 102 \\
& 2 & $3 . .73 \pm 0.18$ & 97.5 \\
\hline Urine A & ----- & $3.12 \pm 0.16$ & ----- \\
& 2 & $5.15 \pm 0.28$ & 101.5 \\
& 3 & $6.09 \pm 0.32$ & 99.0 \\
\hline Urine B & ----- & $7.45 \pm 0.33$ & ----- \\
& 5 & $12.32 \pm 0.65$ & 97.4 \\
& 10 & $17.38 \pm 0.32$ & 99.3
\end{tabular}

a Mean of five determinations \pm confidence interval $(\mathrm{P}=0.95)$

- Urine diluted with DW(1::5) proposed method for determining blood and urine mercury was shown by CRM, NIST in Table 2 .

Also Statistical parameters for determining mercury in blood and briefing air sample were calculated in Table 3. In addition, the results of mercury concentration in blood samples of worker and control were shown in Figure 6.

\section{Conclusions}

Mercury has toxic effect in humans. In high exposures, observed mostly in occupational settings, the severity of response correlates with the duration and intensity of the exposure. Increase mercury exposure depended on time of working and volume of air briefing which was determined based on NIOSH 6009. The results showed us, the mercury concentration in human blood/urine and briefing air in workers were higher than control group. Also, the increasing mercury doses in human blood and briefing air may be lead to an important neuropsychological problem in workers. Therefore, the concentration of mercury in human blood and briefing air is very important factor that must be

Table 2. Analytical results of mercury determination in certified reference material (CRM)

\begin{tabular}{lllll}
\hline Analyte & CRM & Certified Value $\left(\boldsymbol{\mu g} \mathbf{L}^{-1}\right)$ & Found $\left(\boldsymbol{\mu g} \mathbf{L}^{-1}\right)$ & Recovery\% \\
\hline Mercury & NIST SRM 3133 Lot 061204 & $6.50 \pm 0.29$ & $6.38 \pm 0.33$ & 98.2 \\
\hline
\end{tabular}

Mean value \pm standard deviation based on three replicate measurements. 
Table 3. Statistical parameters for determining mercury in blood and briefing air sample by BPDC

\begin{tabular}{lllll}
\hline sample & Mean Conc. & Median Conc. & RSD\% & Range Conc. \\
\hline${ }^{\text {a }}$ Worker & $25.37 \pm 0.93$ & $20.15 \pm 0.57$ & 3.6 & $4.0-52$ \\
${ }^{\text {a }}$ control group & $1.15 \pm 0.08$ & $0.94 \pm 0.04$ & 4.2 & $0.7-5.0$ \\
${ }^{\mathrm{b}}$ Worker & $32.72 \pm 2.24$ & $29.81 \pm 1.08$ & 2.7 & $8.0-64$ \\
${ }^{\mathrm{b}}$ control group & $0.74 \pm 0.03$ & $0.62 \pm 0.02$ & 2.9 & $0.2-1.1$ \\
${ }^{\mathrm{c}}$ Worker & $0.045 \pm 0.01$ & $0.038 \pm 0.01$ & 4.4 & $0.01-0.05$ \\
${ }^{\mathrm{c}}$ control group & $\mathrm{ND}$ & $\mathrm{ND}$ & --- & $\mathrm{ND}$ \\
\hline
\end{tabular}

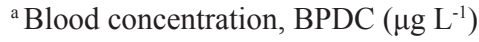

${ }^{\mathrm{b}}$ Urine concentration, BPDC $\left(\mu \mathrm{g} \mathrm{L}^{-1}\right)$

${ }^{\mathrm{c}}$ Briefing air concentration $\left(\mathrm{mg} \mathrm{m}^{-3}\right)$

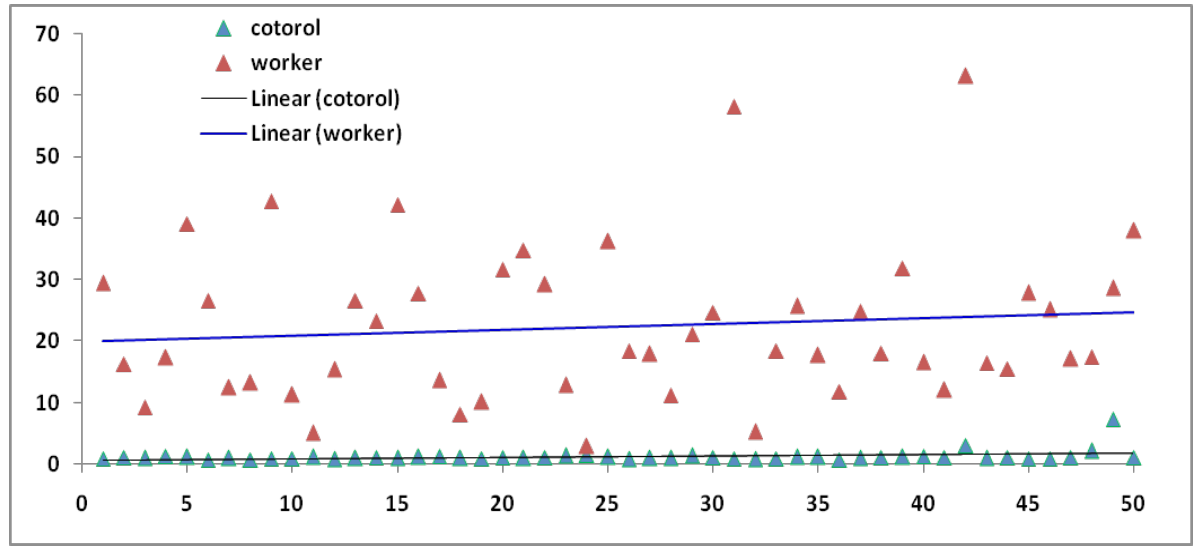

Fig. 6. Dispersive of blood mercury concentration in worker and control group

controlled and determined in industrial workers. In this study the precise and accurate method based on BPDC was used for mercury determination in blood and urine samples by ULLME coupled with FI-CVAAS. The experimental showed, the concentration mercury in worker were higher than OSHA/ACGHI references.

\section{Acknowledgements}

Authors thank to occupational health engineering department of Qom University of medical sciences.

\section{References}

[1] WHO. Elemental Mercury and Inorganic Mercury Compounds, Human Health Aspects, Concise International Chemical Assessment Document 50. World Health Organization, Geneva, 2003.

[2] T. Ohno, M. Sakamoto, T. Kurosawa, M. Dakeishi, T. Iwata, K. Murata, Total mercury levels in hair, toenail and urine among women free from occupational exposure and their relations to renal tubular function, Environ. Res., 103 (2007)191198.

[3] A. Kingman, T. Albertini, LJ. Brown, Mercury concentrations in urine and whole blood associated with amalgam exposure in a US military population. J. Dent. Res., 77 (1998) 461-471.

[4] M.Kampa, E. Castanas, Human health effects of air pollution, In. Environ Pollut., 151 (2008) 362-367.

[5] LL. Booze, Elemental mercury exposure: an evidence-based consensus guideline for out-ofhospital management, Clin. Toxicol., 46 (2008) 21-28.

[6] SC. Foo, Neurobehavioral effects in Occupational Chemical Exposure. Environ. Res., 60 (1993) 26773.

[7] WHO, Mercury environmental aspects, environmental health criteria. world health organization, Geneva, 2008.

[8] IARC, beryllium, cadmium, mercury and exposures in the glass manufacturing industry, mercury and mercury compounds, International Agency for Research on Cancer, Vol 58, 1997. 
[9] H V. Warren, S J. Horksy, C E Gould, Quantitative analysis of zinc, copper, lead, molybdenum, bismuth, mercury and arsenic in brain and other tissues from multiple sclerosis and non-multiple sclerosis cases, Sci. Total Environ., 29 (1983) 163171.

[10] T W. Clarkson, L. Magos, G J. Myers, The toxicology of mercury current exposures and clinical manifestation, New Eng. J. Med., 349 (2003) 1731-1737.

[11] M E. Vahter, N K Mottet, L T. Friberg, S B. Lind, J S. Charleston, T M. Burbacher, Demethylation of methyl mercury in different brain sites of Macaca fascicularis monkeys during long-term subclinical methyl mercury exposur, Toxicol. Appl. Pharm., 134 (1995) 273-284.

[12] M B. Pedersen, J C. Hansen, G. Mulvad, H S. Pedersen, M Gregersen, G. Danscher, Mercury accumulations in brains from populations exposed to high and low dietary levels of methyl mercury. Concentration, chemical form and distribution of mercury in brain samples. Int. J. Circumpolar Health, 58 (1999) 96-107.

[13] M. Nylander, L. Friberg, J Weiner, Muscle biopsy as an indicator for predicting mercury concentrations in the brain, Br. J. Ind. Med., 47 (1990) 575-576.

[14] G. Turabelidze, Multiple sclerosis prevalence and possible lead exposure. J. Neurol. Sci., 269 (2009) 158-162.

[15] OSHA, Guidelines for mercury vapor. Occupational safety and health administration, 2008. Available at: www.osha-slc.gov

[16] NIOSH, Centers for disease control and prevention. National Institute for Occupational Safety and Health, guide to chemical hazards, 3th Ed, 2007.

[17] ACGIH, U.S Documentation of the threshold limit values and biological exposure. American Conference of Governmental Industrial Hygienists, 7th Ed, 2011.

[18] N M. Tietz, Clinical Guide to Laboratory Tests. W. B. Saunders, Philadelphia, PA, 8rd Ed, 2010.

[19] NIOSH, Documentation of the threshold limit values and biological exposure indices. National Institute for Occupational Safety and Health, Cincinnati, OH., 7th Ed., 2001.

[20] Y. Cai, Speciation and analysis of mercury, arsenic, and selenium by atomic fluorescence spectrometry, TrAC Trends Anal. 19 (2000) 62-66.
[21] Gao, Ying, Determination and speciation of mercury in environmental and biological samples by analytical atomic spectrometry, Microchem. J., 103 (2012) 1-14.

[22] J. Szkoda, J. Zmudzki, A. Grzebalska, "Determination of total mercury in biological material by atomic absorption spectrometry method, J. Bull. Vet. Inst. Pulawy, 50 (2006) 363.

[23] H. Erxleben, R. Jaromir, Atomic absorption spectroscopy for mercury, automated by sequential injection and miniaturized in lab-on-valve system, Anal. Chem., 77.16 (2005) 5124-5128.

[24] W. Peng, H. Liang, Z Chengbin, H. Xiandeng, E S Ralph, Applications of chemical vapor generation in non-tetrahydroborate media to analytical atomic spectrometry, J. Anal. Atom. Spec., 25.8 (2010) 1217-1246.

[25] CF. Harrington, the speciation of mercury and organomercury compounds by using highperformance liquid chromatography, TrAC, Trends Anal. Chem., 19 (2000) 167-179.

[26] CJ, Cappon, J C Smith, Gas-chromatographic determination of inorganic mercury and organomercurials in biological materials, Anal. Chem., 49.3 (1977) 365-369.

[27] SCK. Shum, HM. Pang, RS Houk, Speciation of mercury and lead compounds by microbore column liquid chromatography-inductively coupled plasma mass spectrometry with direct injection nebulization, Anal. Chem., 64 (1992) 2444-2450.

[28] L. N. Liang, G. B. Jiang, J. F. Liu, J. T. Hu, Speciation analysis of mercury in seafood by using high-performance liquid chromatography online coupled with cold-vapor atomic fluorescence spectrometry via a post column microwave digestion, Anal. Chim. Acta, 477 (2003) 131-137.

[29] X Jia, Y Han, X Liu, T Duan, H Chen, Speciation of mercury in water samples by dispersive liquidliquid microextraction combined with high performance liquid chromatography-inductively coupled plasma mass spectrometry, Spectrochim. Acta Part B: Atom. Spec., 66 (2011) 88-92.

[30] S. Mishra, R. M. Tripathi, S. Bhalke, V. K. Shukla, V. D. Puranik, Determination of methylmercury and mercury (II) in a marine ecosystem using solid-phase microextraction gas chromatographymass spectrometry, Anal. Chim. Acta, 551 (2005) 192-198. 
[31] Q. Liu, Determination of mercury and methylmercury in seafood by ion chromatography using photo-induced chemical vapor generation atomic fluorescence spectrometric detection, Microchem. J., 95 (2010) 255-258.

[32] M. Park, H. Yoon, C. Yoon, J. Y. Yu, Estimation of mercury speciation in soil standard reference materials with different extraction methods by ion chromatography coupled with ICP-MS, Environ. Geochem. health, 33 (2011) 49-56.

[33] S. Carneado, R. Peró-Gascón, C. Ibáñez-Palomino, J. F. López-Sáncheza, A. Sahuquillo, Mercury (II) and methylmercury determination in water by liquid chromatography hyphenated to cold vapour atomic fluorescence spectrometry after online short-column preconcentration, Anal. Method., 7 (2015) 2699-2706.

[34]A. Fashi, MR. Yaftian, A. Zamani, Electromembrane extraction-preconcentration followed by microvolume UV-Vis spectrophotometric determination of mercury in water and fish samples, Food chem., 221 (2017) 714-720.

[35] D. M, Sánchez, R. Martín, R. Morante, J. Marín, M.L. MunueraPreconcentration speciation method for mercury compounds in water samples using solid phase extraction followed by reversed phase high performance liquid chromatography, Talanta, 52 (2000) 671-679.

[36] M. Krawczyk, E. Stanisz, Ultrasound-assisted dispersive micro solid-phase extraction with nano$\mathrm{TiO} 2$ as adsorbent for the determination of mercury species, Talanta, 161 (2016): 384-391.

[37] E. Ziaei, A. Mehdinia, A. Jabbari, A novel hierarchical nanobiocomposite of graphene oxidemagnetic chitosan grafted with mercapto as a solid phase extraction sorbent for the determination of mercury ions in environmental water samples, Anal. Chim. Acta, 850 (2014) 49-56.

[38] N. Pourreza, K. Ghanemi, Determination of mercury in water and fish samples by cold vapor atomic absorption spectrometry after solid phase extraction on agar modified with 2-mercaptobenzimidazole, J. Hazard. Mater., 161 (2009) 982-987.

[39] A Krata, K Pyrzyńska, E Bulska, Use of solidphase extraction to eliminate interferences in the determination of mercury by flow-injection $\mathrm{CV}$ AAS, Anal. Bioanal. Chem., 377 (2003) 735-739.

[40] L. Adlnasab, H. Ebrahimzadeh,A.A.Asgharinezhad,
M. Nasiri Aghdam, A. Dehghani, S. Esmaeilpour, preconcentration procedure for determination of ultra-trace mercury (II) in environmental samples employing continuous-flow cold vapor atomic absorption spectrometry, Food anal. Method., 7 (2014) 616-628.

[41] NH Khdary, AG Howard, New solid-phasenanoscavenger for the analytical enrichment of mercury from water, Analyst, 136 (2011) 30043009.

[42] E. Zolfonoun, A. Rouhollahi, A. Semnani, Solidphase extraction and determination of ultra-trace amounts of lead, mercury and cadmium in water samples using octadecyl silica membrane disks modified with 5, 5'-dithiobis (2-nitrobenzoic acid) and atomic absorption spectrometry, Int. J. Environ. Anal. Chem., 88 (2008) 327-336.

[43] Y. Date, et al, Trace-level mercury ion $(\mathrm{Hg} 2+)$ analysis in aqueous sample based on solid-phase extraction followed by microfluidic immunoassay, Anal. Chem., 85 (2012) 434-440.

[44] P. Rivaro, C. Ianni, F. Soggia, R. Frache, Mercury speciation in environmental samples by cold vapour atomic absorption spectrometry with in situ preconcentration on a gold trap, Microchim. Acta, 158 (2007) 345-352.

[45] H. Shirkhanloo, A. Khaligh, H. Zavvar Mousavi, M. M. Eskandari, A. A. Miran-Beigi, Ultra-trace arsenic and mercury speciation and determination in blood samples by ionic liquid-based dispersive liquid-liquid microextraction combined with flow injection-hydride generation/cold vapor atomic absorption spectroscopy, Chem. Paper.. 69 (2015) 779-790.

[46] N. Rajesh, G. Gurulakshmanan, Solid phase extraction and spectrophotometric determination of mercury by adsorption of its diphenylthiocarbazone complex on an alumina column, Spectrochim. Acta Part A: Mol. Biomol. Spec., 69.2 (2008) 391-395.

[47] HI. Ulusoy, R Gürkan, S Ulusoy, Cloud point extraction and spectrophotometric determination of mercury species at trace levels in environmental samples, Talanta, 88 (2012) 516-523.

[48] J. C. de Wuilloud, R. G. Wuilloud, M. F. Silva, R.A. Olsina, L. D. Martinez, Sensitive determination of mercury in tap water by cloud point extraction pre-concentration and flow injection-cold vaporinductively coupled plasma optical emission 
spectrometry, Spectrochim. Acta Part B: Atom. Spec., 57 (2002) 365-374.

[49] A. Nasrollahpour, S. M. J. Moradi, S. E. Moradi. Dispersive solid phase micro-extraction of mercury (II) from environmental water and vegetable samples with ionic liquid modified graphene oxide nanoparticles, J. Serb. Chem. Soc., 82 (2017) 551565.

[50] C. Mitani, A. Kotzamanidou, A.N. Anthemidis, Automated headspace single-drop microextraction via a lab-in-syringe platform for mercury electrothermal atomic absorption spectrometric determination after in situ vapor generation, J. Anal. Atom. Spec., 29 (2014) 1491-1498.

[51] M. Hossien-poor-Zaryabi, et al. "Application of dispersive liquid-liquid micro-extraction using mean centering of ratio spectra method for trace determination of mercury in food and environmental samples. Food Anal. Method., 7 (2014) 352-359.

[52] M. Rezaee, Y. Assadi, M. R. M. Hosseini, E. Aghaee, F. Ahmadi, S. Berijani, Determination of organic compounds in water using dispersive liquid-liquid microextraction, J. Chromatogr. A, 1116 (2006) 1-9.

[53] G. Li, K. H. Row, Utilization of deep eutectic solvents in dispersive liquid-liquid microextraction, TrAC, Trends Anal. Chem., 120 (2019) 115651.

[54] Li, Yanyan, et al, Magnetic effervescent tabletassisted ionic liquid-based dispersive liquid-liquid microextraction of polybrominated diphenyl ethers in liquid matrix samples, Talanta, 195 (2019) 785795. 